\title{
Acúmulo de biomassa e produtividade do girassol cultivado sob adubação orgânica e mineral
}

\author{
Biomass accumulation and productivity of sunflower grown under organic and mineral fertilization \\ Acumulación de biomasa y productividad de girasol cultivado bajo fertilización orgánica y mineral
}

Recebido: 23/04/2021 | Revisado: 02/05/2021 | Aceito: 05/05/2021 | Publicado: 20/05/2021

Gustavo Quereza de Freitas

ORCID: https://orcid.org/0000-0002-8994-7027 Instituto Federal de Educação, Ciência e Tecnologia Goiano, Brasil

E-mail: gustavo.quereza@ifgoiano.edu.br

Fernando Rodrigues Cabral Filho

ORCID: https://orcid.org/0000-0002-5090-5946 Instituto Federal de Educação, Ciência e Tecnologia Goiano, Brasil E-mail: fernandorcfilho@hotmail.com

Marconi Batista Teixeira

ORCID: https://orcid.org/0000-0002-0152-256X Instituto Federal de Educação, Ciência e Tecnologia Goiano, Brasil E-mail: marconibt@gmail.com

Fernando Nobre Cunha

ORCID: https://orcid.org/0000-0001-8489-7625 Instituto Federal de Educação, Ciência e Tecnologia Goiano, Brasil

E-mail: fernandonobrecunha@hotmail.com

Daniely Karen Matias Alves

ORCID: https://orcid.org/0000-0001-7427-7545 Instituto Federal de Educação, Ciência e Tecnologia Goiano, Brasil E-mail: daniely_karen@hotmail.com

Frederico Antonio Loureiro Soares

ORCID: https://orcid.org/0000-0002-4152-5087 Instituto Federal de Educação, Ciência e Tecnologia Goiano, Brasil E-mail: frederico.soares@ifgoiano.edu.br

Nelmício Furtado da Silva

ORCID: https://orcid.org/0000-0001-7055-8075 Instituto Federal de Educação, Ciência e Tecnologia Goiano, Brasil E-mail: nelmiciofurtado@gmail.com

Leonardo Nazário Silva dos Santos

ORCID: https://orcid.org/0000-0002-3951-3888 Instituto Federal de Educação, Ciência e Tecnologia Goiano, Brasil E-mail: leonardo.santos@ifgoiano.edu.br

Wilker Alves Morais

ORCID: https://orcid.org/0000-0003-2336-6518 Instituto Federal de Educação, Ciência e Tecnologia Goiano, Brasil E-mail: wilker.alves.morais@gmail.com

\begin{abstract}
Resumo
O acúmulo de matéria seca no girassol é extremamente importante para a produção de grãos, no qual, quando possui uma adubação inadequada a produção é prejudicada. Objetivou-se avaliar o acúmulo de biomassa e a produtividade de grãos do girassol adubado com formulados de NPK (mineral e organomineral). O experimento foi realizado em uma casa de vegetação, localizada em área experimental do IFGoiano - Campus Rio Verde - GO, no município de Rio Verde, Goiás. O delineamento experimental utilizado foi em blocos ao acaso, analisado em esquema fatorial $4 \times 2$ com três repetições. Os tratamentos consistiram em quatro doses do formulado 04-14-08 NPK: 50, 100, 150 e $200 \%$ da recomendação que correspondem, $90 \mathrm{~kg} \mathrm{ha}^{-1}$ de $\mathrm{N}, 180 \mathrm{~kg} \mathrm{ha}^{-1}$ de P e $40 \mathrm{~kg} \mathrm{ha}^{-1}$ de K para a cultura do girassol e duas fontes mineral e organomineral. A aplicação dos formulados nas respectivas fontes e dosagens foi realizado na semeadura. Foram efetuadas as análises de acúmulo de matéria seca, massa de água e produtividade de grãos. A fonte NPK mineral proporciona maior massa fresca das folhas, massa seca do caule, massa de água e massa seca da parte aérea do girassol do que a fonte orgnomineral. As doses de 162 e $138 \%$ da recomendação de NPK, via fonte mineral e organomineral proporcionam a maior produtividade de grãos para a cultura do girassol, respectivamente.
\end{abstract}

Palavras-chave: Helianthus annuus; Nitrogênio; Fósforo; Potássio. 


\begin{abstract}
The accumulation of dry matter in the sunflower is extremely important for grain production, in which, when it has inadequate fertilization, production is impaired. The objective was to evaluate the biomass accumulation and grain yield of sunflower fertilized with NPK formulations (mineral and organomineral). The experiment was carried out in a greenhouse, located in an experimental area of IFGoiano - Campus Rio Verde - GO, in the municipality of Rio Verde, Goiás. The experimental design used was in randomized blocks, analyzed in a $4 \times 2$ factorial scheme with three repetitions. The treatments consisted of four doses of the formulated 04-14-08 NPK: 50, 100, 150 and $200 \%$ of the corresponding recommendation, $90 \mathrm{~kg} \mathrm{ha}^{-1}$ of $\mathrm{N}, 180 \mathrm{~kg} \mathrm{ha}^{-1}$ of $\mathrm{P}$ and $40 \mathrm{~kg} \mathrm{ha}^{-1}$ of $\mathrm{K}$ for sunflower culture and two mineral and organomineral sources. The application of formulations in the respective sources and dosages was carried out at sowing. Analyzes of dry matter accumulation, water mass and grain yield were performed. The mineral NPK source provides greater fresh mass of the leaves, dry mass of the stem, water mass and dry mass of the aerial part of the sunflower than the orgnomineral source. The doses of 162 and $138 \%$ of the NPK recommendation, via mineral and organomineral source, provide the highest grain yield for sunflower cultivation, respectively.
\end{abstract}

Keywords: Helianthus annuus; Nitrogen; Phosphor; Potassium.

\title{
Resumen
}

La acumulación de materia seca en el girasol es de suma importancia para la producción de granos, en los que, cuando tiene una fertilización inadecuada, se deteriora la producción. El objetivo fue evaluar la acumulación de biomasa y el rendimiento de grano de girasol fertilizado con formulaciones NPK (mineral y organomineral). El experimento se llevó a cabo en un invernadero, ubicado en un área experimental de IFGoiano - Campus Rio Verde - GO, en el municipio de Rio Verde, Goiás. El diseño experimental utilizado fue en bloques al azar, analizados en una factorial 4 $\times 2$. esquema con tres repeticiones. Los tratamientos consistieron en cuatro dosis del NPK formulado 04-14-08: 50, 100, 150 y $200 \%$ de la recomendación correspondiente, $90 \mathrm{~kg} \mathrm{ha}^{-1} \mathrm{de} \mathrm{N}, 180 \mathrm{~kg} \mathrm{ha}^{-1}$ de $\mathrm{P}$ y $40 \mathrm{~kg} \mathrm{ha}^{-1} \mathrm{de} \mathrm{K}$ para el cultivo de girasol y dos fuentes minerales y organominerales. La aplicación de formulaciones en las respectivas fuentes y dosis se realizó en el momento de la siembra. Se realizaron análisis de acumulación de materia seca, masa de agua y rendimiento de grano. La fuente mineral NPK aporta mayor masa fresca de las hojas, masa seca del tallo, masa de agua y masa seca de la parte aérea del girasol que la fuente orgnomineral. Las dosis de 162 y $138 \%$ de la recomendación de NPK, a través de fuente mineral y organomineral, proporcionan el mayor rendimiento de grano para el cultivo de girasol, respectivamente.

Palabras clave: Helianthus annuus; Nitrógeno; Fósforo; Potasio.

\section{Introdução}

A cultura do girassol (Helianthus annuus, L.) e de outras oleaginosas vem ganhando posição de destaque na economia do país, justificando, assim, a busca incessante de novas informações no intuito de melhorar as condições de cultivos para, assim, reduzir riscos e prejuízos. O girassol. por possuir propriedades físico-químicas que se adequam ao clima, é cultivado em todos os continentes, sendo sua origem Norte Americano (Gomes et al., 2003).

A determinação de qual fertilizante usar na produção do girassol se faz necessária, pois a falta de nutrientes afetam as características das plantas e interferem no acúmulo de massa seca e a estacionalidade de produção, logo a inadequada nutrição das plantas, concorre para baixos índices de produtividade, devido à falta de gestão no programa de adubação, haja vista que, para atingir elevados rendimentos, a cultura necessita ter as suas exigências nutricionais plenamente satisfeitas, visto que produtividades elevadas implicam grande extração de nutrientes (Gomes et al., 2007; Tonato et al., 2010; Teixeira Filho et al., 2015; Coelho et al., 2017).

Dentre as práticas de manejo, a adubação é um dos fatores que mais contribui para a obtenção de altos rendimentos da cultura, entretanto, muitas vezes as doses de fertilizantes estabelecidas nos manuais de recomendação, não garantem altos índices de produtividade, muito provavelmente devido as alterações de ciclo e do aumento do potencial produtivo das novas variedades, em comparação as variedades utilizadas para elaboração dos manuais de recomendação (Bernardi et al., 2009; Guareschi et al., 2011; Cruz et al., 2018); além disso vale destacar que vem crescendo a utilização de outras fontes como a dos fertilizantes organominerais, sendo que estas fontes se caracterizam pela mistura de uma fonte de matéria orgânica a um fertilizante mineral, consistindo em alternativas para propiciar maior rendimento das culturas, menor impacto ambiental, redução dos custos de produção e melhor qualidade da produção (Andrade et al., 2012; Viana et al., 2013; Santos et al., 2020). 
Com isto verifica-se que é muito importante a ampliação do conhecimento da cultura do girassol e do seu ambiente de produção, aliada à avaliação dos cenários agrícolas, para o estabelecimento de sistemas de produção eficientes e racionais, objetivando a obtenção de resultados satisfatórios quanto a produtividade, rendimento, qualidade do produto e sustentabilidade da atividade (Queiroz et al., 2011).

Objetivou-se avaliar o acúmulo de biomassa e a produtividade de grãos do girassol adubado com formulados de NPK (mineral e organomineral).

\section{Metodologia}

O experimento foi realizado em uma casa de vegetação, localizada em área experimental do IFGoiano - Campus Rio Verde - GO, no município de Rio Verde, Goiás, cujo clima é Aw (tropical), com chuva nos meses de outubro a maio, e com seca nos meses de junho a setembro, conforme classificação de Alvares et al. (2013) e Köppen (2013), temperatura média anual entre 20 e $30^{\circ} \mathrm{C}$ e média pluviométrica anual acima de $1500 \mathrm{~mm}$.

O solo utilizado para realizar o enchimento dos vasos foi o Latossolo Vermelho distroférrico (LVdf), argiloso, fase Cerrado (Santos et al., 2018), coletado na profundidade de até $0,20 \mathrm{~m}$. O solo foi colocado em unidades experimentais compostas por vasos plásticos de $30 \mathrm{~L}$.

Tabela 1. Análise química e granulométrica do solo utilizado para enchimento dos vasos.

\begin{tabular}{|c|c|c|c|c|c|c|c|c|c|}
\hline $\mathrm{Ca}$ & $\mathrm{Mg}$ & $\mathrm{Ca}+\mathrm{Mg}$ & $\mathrm{Al}$ & $\mathrm{H}+\mathrm{Al}$ & K & $\mathrm{K}$ & $\mathrm{S}$ & $\mathrm{P}$ & $\mathrm{CaCl}_{2}$ \\
\hline \multicolumn{6}{|c|}{-- } & \multicolumn{3}{|c|}{-------- $\mathrm{mg} \mathrm{dm}{ }^{-3}$-------- } & $\mathrm{pH}$ \\
\hline 0,94 & 0,86 & 1,8 & 0,03 & 2,39 & 0,32 & 126 & 5,0 & 1,09 & 5,2 \\
\hline $\mathrm{Na}$ & $\mathrm{Fe}$ & $\mathrm{Mn}$ & $\mathrm{Cu}$ & $\mathrm{Zn}$ & B & CTC & SB & $\mathrm{V} \%$ & $\mathrm{~m} \%$ \\
\hline \multicolumn{6}{|c|}{------ Micronutrientes $\left(\mathrm{mg} \mathrm{dm}^{-3}\right)$------ } & \multicolumn{2}{|c|}{$\mathrm{cmol}_{\mathrm{c}} \mathrm{dm}^{-3}$} & Sat. Bases & Sat. Al \\
\hline 1,0 & 21,4 & 22,52 & 4,25 & 1,13 & 0,09 & 4,51 & 2,12 & 47 & 1,4 \\
\hline \multicolumn{3}{|c|}{ Textura $\left(\mathrm{g} \mathrm{kg}^{-1}\right)$} & M.O. & $\mathrm{Ca} / \mathrm{Mg}$ & $\mathrm{Ca} / \mathrm{K}$ & $\mathrm{Mg} / \mathrm{K}$ & $\mathrm{Ca} / \mathrm{CTC}$ & $\mathrm{Mg} / \mathrm{CTC}$ & $\mathrm{K} / \mathrm{CTC}$ \\
\hline Argila & Silte & Areia & $\mathrm{g} \mathrm{dm}^{-3}$ & & -- & $-\mathrm{R}$ & entre ba & ------ & \\
\hline 450 & 80 & 470 & 36,3 & 1,1 & 2,9 & 2,7 & 20,84 & 19,07 & 7,10 \\
\hline
\end{tabular}

$\mathrm{P}$ (Mel), K, Na, $\mathrm{Cu}, \mathrm{Fe}, \mathrm{Mn}$ e Zn (Melich 1); $\mathrm{Ca}, \mathrm{Mg}$ e Al (KCl 1N); $\mathrm{S}\left(\mathrm{Ca}_{(} \mathrm{H}_{2} \mathrm{PO}_{4}\right)_{2}$ em HOAc); M.O. (Método colorimétrico); B $\left(\mathrm{BaCl}_{2}\right)$. Fonte: Autores.

O delineamento experimental utilizado foi em blocos ao acaso, analisado em esquema fatorial $4 \times 2$ com três repetições. Os tratamentos consistiram em quatro doses do formulado 04-14-08 NPK: 50, 100, 150 e 200\% da recomendação que correspondem, $90 \mathrm{kgha}^{-1}$ de N, $180 \mathrm{kgha}^{-1}$ de P e $40 \mathrm{kgha}^{-1}$ de K para a cultura do girassol, segundo Sousa e Lobato (2004) e duas fontes mineral e organomineral.

A aplicação tratamentos foi efetuado no momento da semeadura, além dessas no decorrer do experimento outras adubações foram realizadas: adubações de cobertura aos 30 e 50 dias após a semeadura, nas dosagens de 1,6 g de ureia e $0,21 \mathrm{~g}$ de ácido bórico aos 30 dias após a semeadura (DAS) e de 1,62 g de ureia aos 50 DAS, conforme a análise química do solo.

$\mathrm{Na}$ colheita, realizada ao 90 DAS, foram determinadas as massas frescas e secas do caule (MFC e MSC), massas frescas e secas das folhas (MFF e MSF), massas frescas e secas do capítulo (MFCAP e MSCAP) e massa seca da parte aérea (MSPA). Além disto, a massa de água total na planta (MA) e os teores de água do caule (TAC) e os teores de água do capítulo (TACAP). 
A massa seca da folha, do caule, do capítulo e da parte aérea foram determinadas da seguinte forma: as plantas foram divididas em caule, folha + pecíolo e capítulo, posteriormente acondicionadas em sacos de papel (identificados com os tratamentos) e colocadas a estufa de ventilação forçada de ar a $65^{\circ} \mathrm{C}$ por período de $72 \mathrm{~h}$, até massa constante, desta forma, as massas secas da folha, do caule, do capítulo e da parte aérea foram determinadas em balança analítica de precisão (resolução de $0,001 \mathrm{~g}$ ). As outras variáveis analisadas foram a produtividade $\left(\mathrm{kg} \mathrm{há}^{-1}\right)$, massa de grãos por planta (PSGRÃO) e o índice de colheita (razão entre PSGRÃO/MSPA + PSGRÃO).

Os dados foram submetidos à análise de variância, pelo Teste $\mathrm{F}(p<0,05)$, e em casos de significância, as médias referentes as fontes foram comparadas pelo teste de Tukey a 5\% de probabilidade e para as doses foi realizada análise de regressão, utilizando o software SISVAR $^{\circledR}$ (Ferreira, 2011).

\section{Resultados e Discussão}

Ocorreu efeito das fontes na massa fresca das folhas (MFF), massa seca do caule (MSC), massa de água (MA) e massa seca da parte aérea (MSPA) do girassol. Houve interação significativa Fonte $\times$ Dose para a massa fresca do caule (MFC), a massa seca das folhas (MSF), massa fresca do capítulo (MFCAP), massa seca do capítulo (MSCAP), teor de água do caule (TAC) e o teor de água do capítulo (TACAP) do girassol.

$\mathrm{Na}$ Tabela 2, observa-se diferença significativa entre a fonte mineral (M) e organomineral (OM), onde as maiores médias de Massa fresca das folhas (MFF), massa seca do caule (MSC), massa de água (MA) e de massa seca da parte aérea (MSPA) foram obtidas na fonte mineral. As variáveis massa fresca das folhas (MFF), massa seca do caule (MSC), massa de água (MA) e massa seca da parte aérea (MSPA) foram 32,76\% (13,6 g), 33,96\% (12,72 g), 33,90\% (89,94 g) e 24,16\% $(29,12$ g) superiores quando utilizada a fonte mineral, respectivamente. Freitas et al. (2020) constatou que o aumento da dose da fonte organomineral reduziu a massa fresca do caule em $26,50 \mathrm{~g}$ a cada $50 \%$, e quando contratadas as doses de 50 e $200 \%$ verificaram-se uma diminuição de $73,75 \%$ na massa fresca do caule.

Tabela 2. Massa fresca das folhas (MFF), do caule (MSC), da parte aérea (MSPA) e massa de água (MA) de girassol adubado com fonte mineral $(\mathrm{M})$ e organomineral $(\mathrm{OM})$.

\begin{tabular}{ccccc}
\hline Fonte $^{1}$ & MFF & MSC & MA & MSPA \\
\hline & & $37,46 \mathrm{a}$ & $265,31 \mathrm{a}$ & $120,55 \mathrm{a}$ \\
$\mathrm{M}$ & $41,51 \mathrm{a}$ & $24,74 \mathrm{~b}$ & $175,37 \mathrm{~b}$ & $91,43 \mathrm{~b}$ \\
\hline
\end{tabular}

${ }^{1}$ Médias com letras iguais na coluna, não diferem entre si estatisticamente pelo teste de Tukey a 5\% de probabilidade. Fonte: Autores.

A superioridade da fonte mineral nas variáveis analisadas, faz sentido nesse caso se for considerado que a presença de matéria orgânica reduz a absorção de fósforo $(\mathrm{P})$, sendo essas reduções mesmo que em pequenas proporções, tendo em vista que o P é um elemento de grande relevância, participando de vários processos metabólicos nas plantas (Almeida et al., 2016).

Na figura 1A, temos a massa fresca das folhas em função doses de NPK, essa relação é descrita por uma função polinomial, na qual seu ponto de máximo está em 95,2\%. Para a relação entre a massa de água e doses de NPK é expressa por uma função polinomial, como ilustra a figura 1B, tendo seu ponto de máximo nos 105,80\% da dose de NPK. 
Figura 1. Massa fresca das folhas (MFF) e massa de água da parte aérea (MA) do girassol em função das doses de NPK.
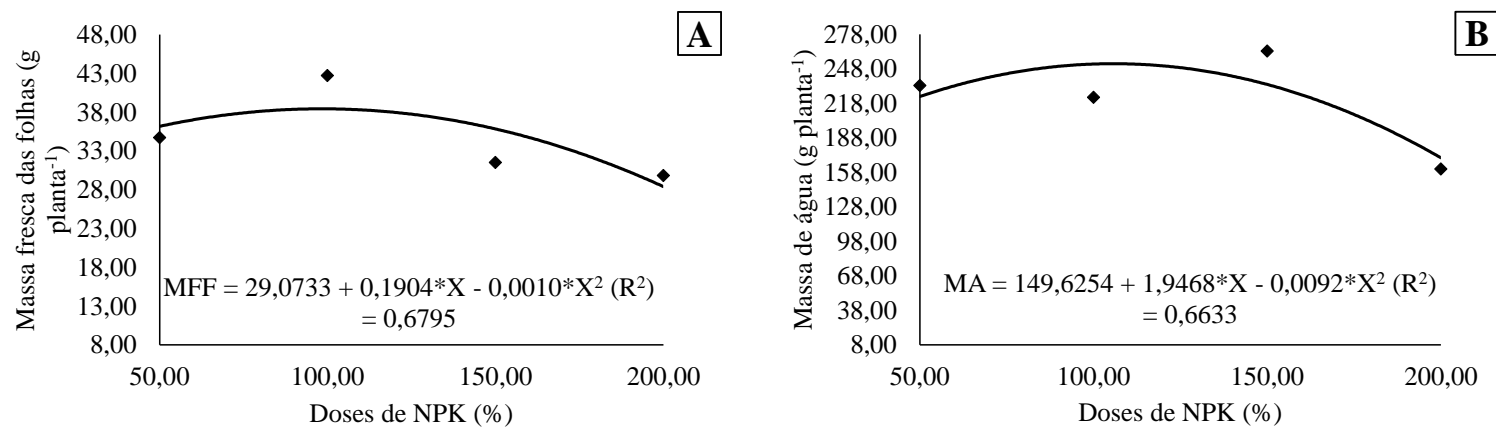

Fonte: Autores.

Na Figura 2A, pode-se verificar diferença na adequação dos modelos da MSF do girassol, quando comparada as duas fontes de NPK. Para a fonte organomineral, a MSF do girassol se adequou ao modelo de regressão linear decrescente, em que, a cada incremento de 50\% na dose ocorreu uma diminuição de 3,68\% na MSF do girassol $\left(0,73 \mathrm{~g}\right.$ planta $\left.^{-1}\right)$. Já para a fonte mineral (M), a MSF de girassol adequou-se a uma equação polinomial quadrática, cuja dose de 122,04\% promoveu a maior MSF do girassol, igual a 30,76 g planta ${ }^{-1}$. Sendo, 20,24 e 23,71\% superior a MSF estimada nas doses de 50\% e 200\%. Dantas et al. (2015) analisando a massa seca das folhas, observaram os valores máximos de 15,10; 17,74; 23,01 e 30,33 g, verificou-se ainda que para essa matéria seca a máxima resposta obtida se correlacionou com a maior dose de adubação aplicada ao solo.

Ocorreu diferença significativa nas doses de 100, 150 e 200\% quando contratada as fontes utilizadas (Figura 2B), em que a fonte M promoveu a maior MSF do girassol, na ordem de 71,83\% (13,61 $\left.\mathrm{g} \mathrm{planta}^{-1}\right), 27,70 \%$ (7,25 $\left.\mathrm{g} \mathrm{planta}^{-1}\right)$ e $22,77 \%$ $\left(5,19 \mathrm{~g} \mathrm{planta}^{-1}\right)$ quando comparada com a fonte $\mathrm{OM}$, respectivamente.

Figura 2. A massa seca das folhas (MSF) do girassol em função das fontes de NPK (Mineral - M e Organomineral - OM).
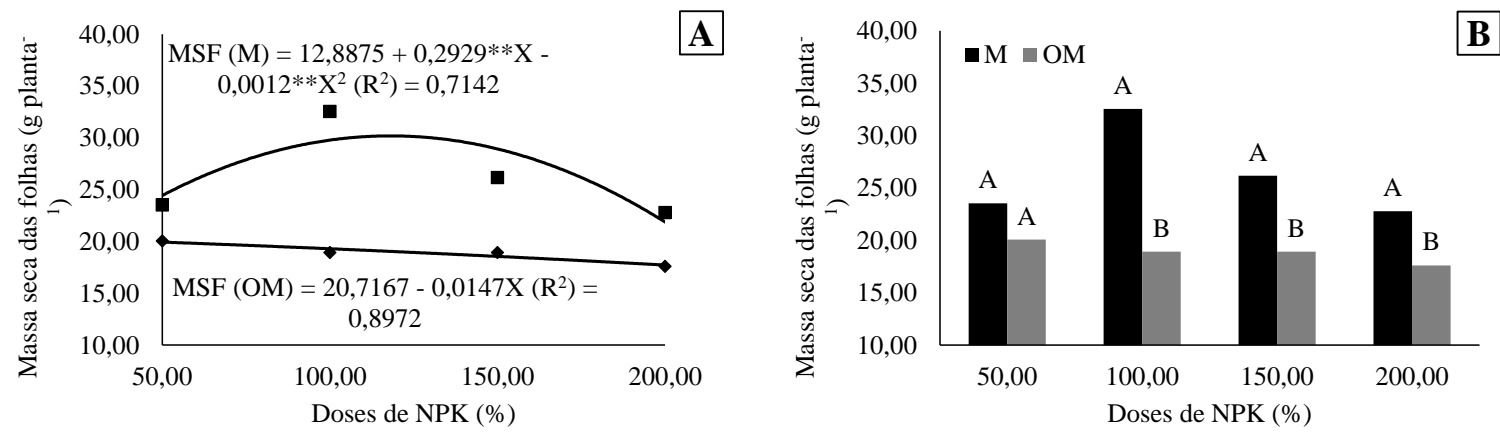

Fonte: Autores.

Na Figura 3A, verifica-se diferença nas equações da MFCAP do girassol, quando comparada as duas fontes de NPK. Quando considerado a fonte mineral (M), a MFCAP do girassol se adequou ao modelo de regressão linear decrescente, em que, a cada incremento de 50\% na dose ocorreu uma diminuição de 11,68\% na MFCAP do girassol (29,31 g planta $\left.{ }^{-1}\right)$. Já para a fonte organomineral (OM), a MFCAP do girassol adequou-se a uma equação polinomial quadrática, onde a dose de 117,30\% promoveu a maior MFCAP do girassol, igual a 180,61 $\mathrm{g} \mathrm{planta}^{-1}$, sendo, 32,47\% superior a MFCAP estimada na dose de $50 \%$. Nobre et al. (2010) ao estudarem o rendimento do girassol submetido a diferentes reposições hídrica com efluentes domésticos e adubação orgânica, observaram um incremento de 6,5\% da biomassa fresca do capítulo. 
A diferença significativa foi verificada apenas nas doses de 50 e100\% quando confrontadas as fontes utilizadas (Figura 3B), em que a fonte mineral promoveu a maior MFCAP do girassol, na ordem de 33,62\% (81,94 g planta $\left.\mathrm{g}^{-1}\right)$ e $36,29 \%(86,78 \mathrm{~g}$ planta $^{-1}$ ) quando comparada com a fonte OM, respectivamente.

Figura 3. A massa fresca do capítulo (MFCAP) do girassol em função das fontes de NPK (Mineral - M e Organomineral $\mathrm{OM})$.
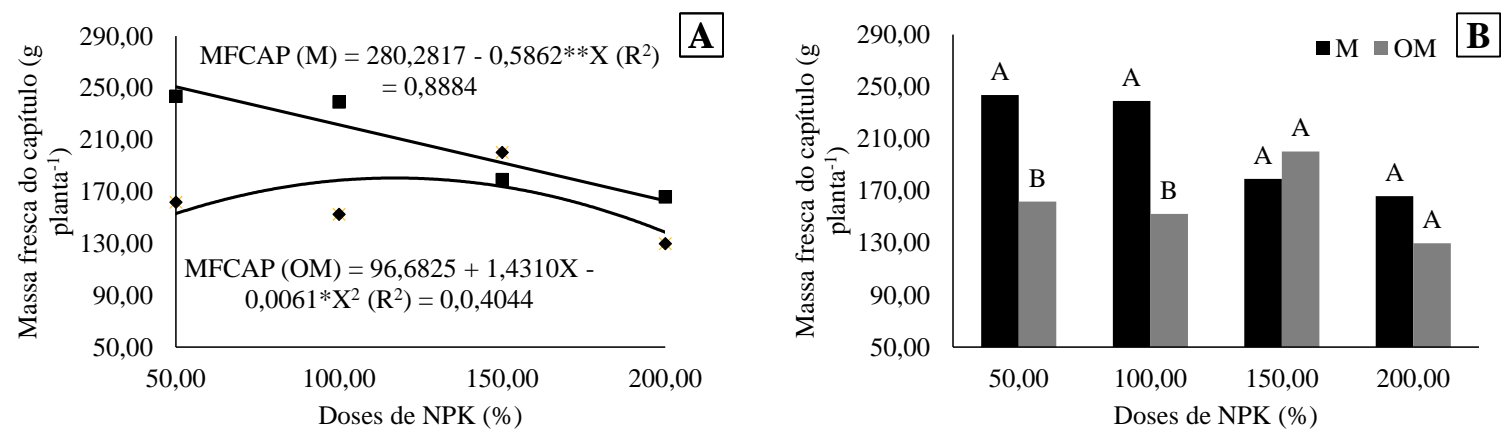

Fonte: Autores.

A cada aumento de 50\% na dose observou um incremento de 5,78\% na MSCAP (3,03 $\left.\mathrm{g} \mathrm{planta}^{-1}\right)$ quando utilizado a fonte OM, enquanto para a fonte mineral, a MSCAP do girassol adequou-se a uma equação polinomial quadrática, onde a dose de $171,25 \%$ promove a maior MSCAP do girassol, igual a 49,14 $\mathrm{g}_{\text {planta }}{ }^{-1}$, sendo, 32,37 e 2,62\% inferior a MSCAP do girassol estimado nas doses de $50 \%$ e $200 \%$ (Figura 4A); geralmente ocorre redução de massa seca e do rendimento das plantas com deficiência nutricional, logo quando há o acúmulo crescente de massa seca do capítulo isto implica em uma absorção contínua de nutrientes pelas plantas os quais são retirados com maior intensidade entre o período de florescimento e a maturação fisiológica dos aquênios, propiciando uma produção de matéria seca mais elevada (Castro et al. 2010; Dantas et al., 2015)

Notou-se diferença significativa nas doses de 50 e 100\% quando confrontada as fontes (Figura 4B), em que a fonte mineral promove a maior MSCAP do girassol, na ordem de 41,38\% (29,80 $\left.\mathrm{g}_{\text {planta }}^{-1}\right)$ e 22,23\% (13,01 $\left.\mathrm{g} \mathrm{planta}^{-1}\right) \mathrm{quando}$ comparada com a fonte OM, respectivamente.

Figura 4. A massa seca do capítulo (MSCAP) do girassol em função das fontes de NPK (Mineral - M e Organomineral $\mathrm{OM})$.
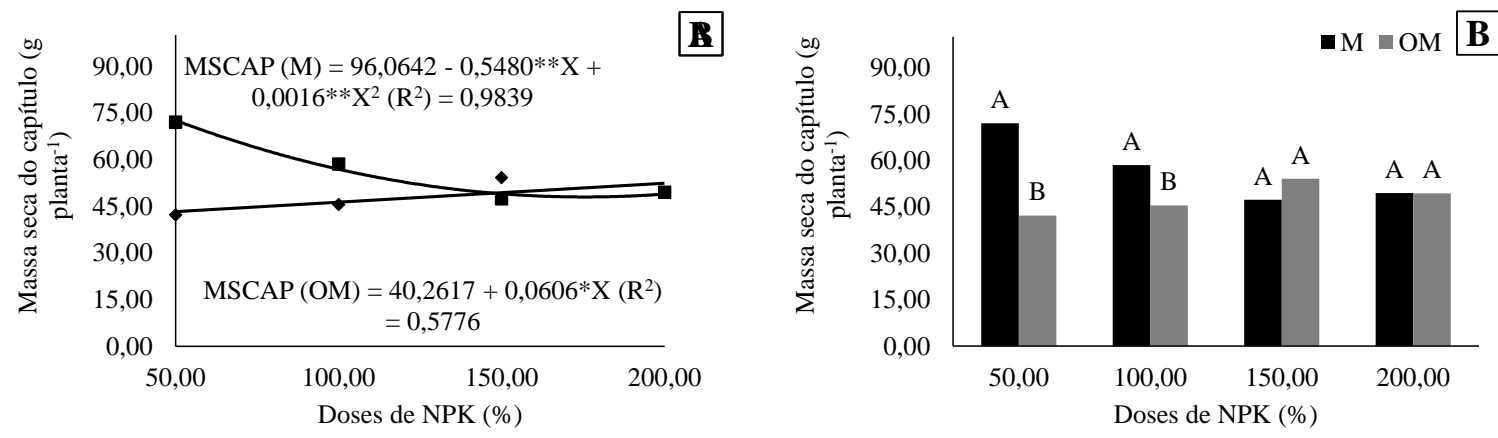

Fonte: Autores. 
Contrastante aos resultados encontrados neste estudo, Oliveira (2018) concluiu que a fonte OM promoveu efeito superior no diâmetro de colmo, largura da folha e na produtividade de grãos do milho, quando comparada com a fonte mineral. Tendo como justificativa a maior disponibilidade de nutrientes, efeito residual, menor adsorção do P no solo devido a presença da matéria orgânica fornecida pela fonte e menor lixiviação de potássio (Garcia et al., 2015; Almeida et al., 2016; Malaquias; Santos, 2017).

Para os índices produtivos não ocorreu efeito isolado das fontes e das doses utilizadas, apenas efeito de interação, em que, esse efeito foi significativo para a massa de grãos por planta (PSGRAO), produtividade de grãos (PROD) e o índice de colheita (IC) do girassol.

Pode-se verificar na Figura 5A semelhança no comportamento do PSGRAO do girassol, quando compara as duas fontes de NPK. Para ambas as fontes, M e OM, o PSGRAO se adequou ao modelo de regressão polinomial quadrático, onde a dose de 162,09\% para a fonte M promoveu o maior PSGRAO, igual a 42,01 $\mathrm{g} \mathrm{planta}^{-1}$, sendo, 68,78 e 7,86\% superior ao PSGRAO do girassol estimado nas doses de 50 e 200\%, respectivamente. Rosset et al. (2016) observaram que a adubação organomineral como forma de complementar a mineral efetuada no plantio das culturas, promove o incremento da massa seca dos grãos, da produção e o do rendimento, quando se comparado àquele que foi adubado apenas com a adubação mineral.

Observou-se diferença significativa nas doses de 50, 150 e 200\% quando confrontado as fontes (Figura 5B), em que a fonte M promoveu o maior PSGRAO do girassol nas doses de 150 e 200\%, na ordem de 31,81\% (14,39 $\left.\mathrm{g} \mathrm{planta}^{-1}\right)$ e 25,59\% $\left(9,67 \mathrm{~g} \mathrm{planta}^{-1}\right)$, respectivamente. Na dose de $50 \%$ a fonte OM promoveu o maior PSGRAO ao girassol, superior $14,24 \%$ $\left(2,37 \mathrm{~g} \mathrm{planta}^{-1}\right)$ em comparação ao obtido quando se utilizada a fonte $\mathrm{M}$.

Figura 5. A massa dos grãos por planta (PSGRAO) do girassol em função das fontes de NPK (Mineral - M e Organomineral $\mathrm{OM})$.
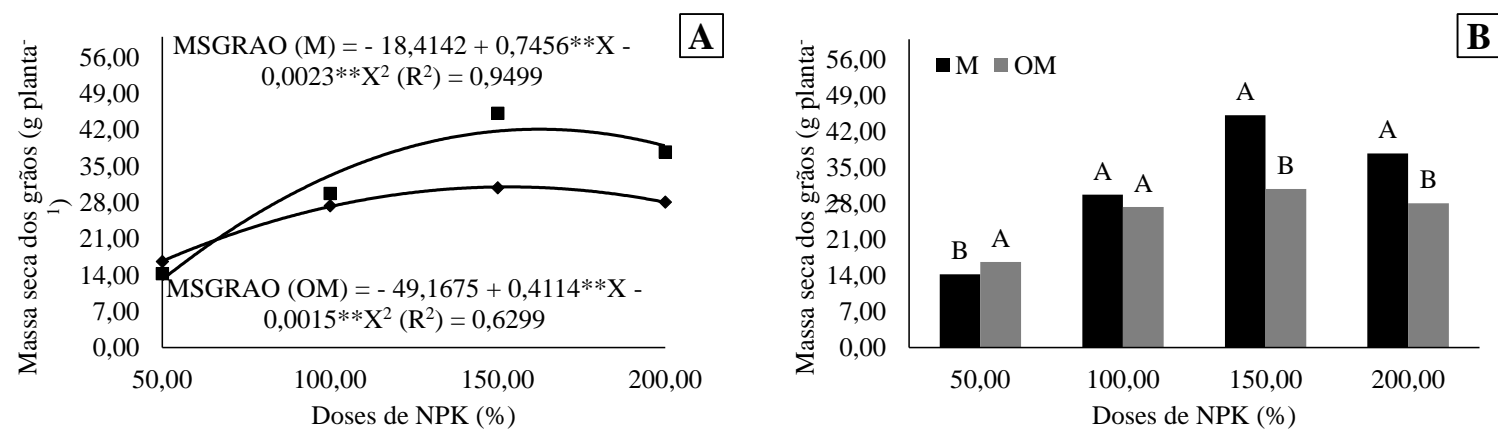

Fonte: Autores.

Resultados semelhantes para a massa seca de grãos foram encontrados por trabalhos realizados por Pereira et al. (2012) e Costa et al. (2018), com as culturas do milho e da soja em função da adubação com diferentes doses de adubação organomineral, em que, a adubação mineral e organomineral apresentaram diferença significativas na massa seca dos grãos.

Na Figura 6A, verifica-se semelhança no comportamento da produtividade de grãos (PROD) do girassol, quando se confronta as duas fontes de NPK. Para ambas as fontes, M e OM, a PROD se adequou ao modelo de regressão polinomial quadrática, onde a dose de $162 \%$ para a fonte $\mathrm{Me}$ e $138 \%$ para a fonte OM promoveu a maior PROD, igual a 2318,13 $\mathrm{kg} \mathrm{ha}^{-1} \mathrm{e}$ $1570 \mathrm{~kg} \mathrm{ha}^{-1}$. Sendo, 68,48 e 7,67\% superior a PROD estimada nas doses de 50 e $200 \%$ na fonte mineral, respectivamente.

O maior valor de produtividade dos grãos de girassol com adubação organomineral em comparação com a produtividade obtida quando foi usada a fonte mineral, em uma dose de $50 \%$ da recomendação, é um indicativo dos benefícios 
a médio e longo prazo da fração orgânica desta fonte, como resultante do aumento da fertilidade do solo, devido ao incremento de matéria orgânica e outros nutrientes, ou seja, melhoria dos atributos físico-químicos do solo (Higashikawa et al., 2017).

Verificou-se diferença nas doses de 50, 150 e 200\% quando confrontadas as fontes (Figura 6B), em que a fonte M promoveu a maior PROD do girassol nas doses de 150 e 200\%, na ordem de 31,81\% (791,56 kg ha-1) e 25,59\% (531,81 kg ha$\left.{ }^{1}\right)$, respectivamente. Na dose de 50\% a fonte OM promoveu a maior PROD ao girassol, superior $14,24 \%\left(130,39 \mathrm{~kg} \mathrm{ha}^{-1}\right) \mathrm{em}^{-1}$ comparação ao obtido quando foi usada a fonte $\mathrm{M}$.

Figura 6. A produtividade de grãos (PROD) em função das fontes de NPK (Mineral - M e Organomineral - OM) do girassol.
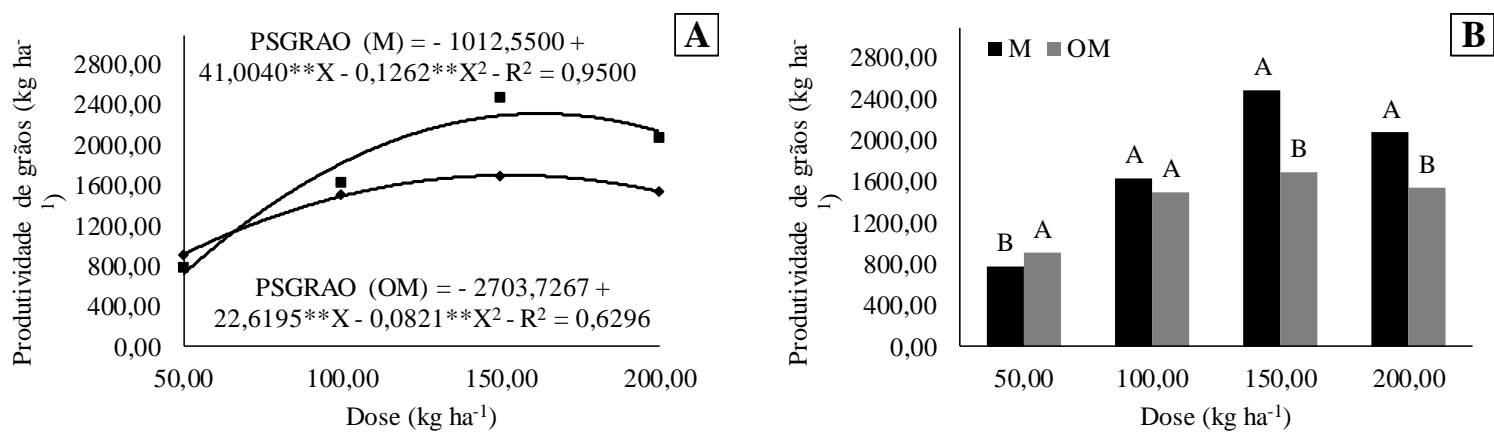

Fonte: Autores.

A elevação da dose a partir da citada anteriormente provocou reduções na produtividade, quando se utilizada a fonte M, este fato pode estar relacionado a composição do fertilizante mineral, em que, as matérias primas utilizadas, principalmente a ureia e cloreto de potássio, são de alta solubilidade, afetando a disponibilidade dos nutrientes (Costa et al., 2018). A dose de $50 \%$ foi a que proporcionou a menor produtividade de grãos do girassol, devido a limitação de nutrientes para que a planta se desenvolve-se adequadamente.

Na Figura 7A, verifica-se semelhança no comportamento do IC do girassol, quando confrontada as fontes de NPK. Para ambas as fontes, M e OM, o IC se adequou ao modelo de regressão polinomial quadrática, onde a dose de 194,44\% para a fonte M promoveu o maior IC, igual a 0,29, sendo, $65,43 \%$ superior ao IC estimado na dose de $50 \%$. Por conta do efeito residual, diversos estudos evidenciam a influência positiva dos adubos orgânicos no $\mathrm{pH}$ do solo, aumento da saturação por bases e da capacidade de troca catiônica, com isto pode-se verificar uma melhora na qualidade do solo, tornando-o capaz de fornecer condições adequadas para o crescimento, rendimento e índice de colheita das culturas (Kurtz, 2013; Higashikawa et al., 2017).

Observou diferença apenas nas doses de 50 e 150\% quando confrontada as fontes (Figura 7B), em que a fonte M promoveu o maior IC na dose de $150 \%$, na ordem de $11,23 \%(0,03)$. Na dose de $50 \%$ a fonte OM promoveu o maior IC ao girassol, superior $36,15 \%(0,06)$ em comparação ao girassol adubado com a fonte $\mathrm{M}$. 
Figura 7. O índice de colheita (IC) do girassol em função das fontes de NPK (Mineral - M e Organomineral - OM).
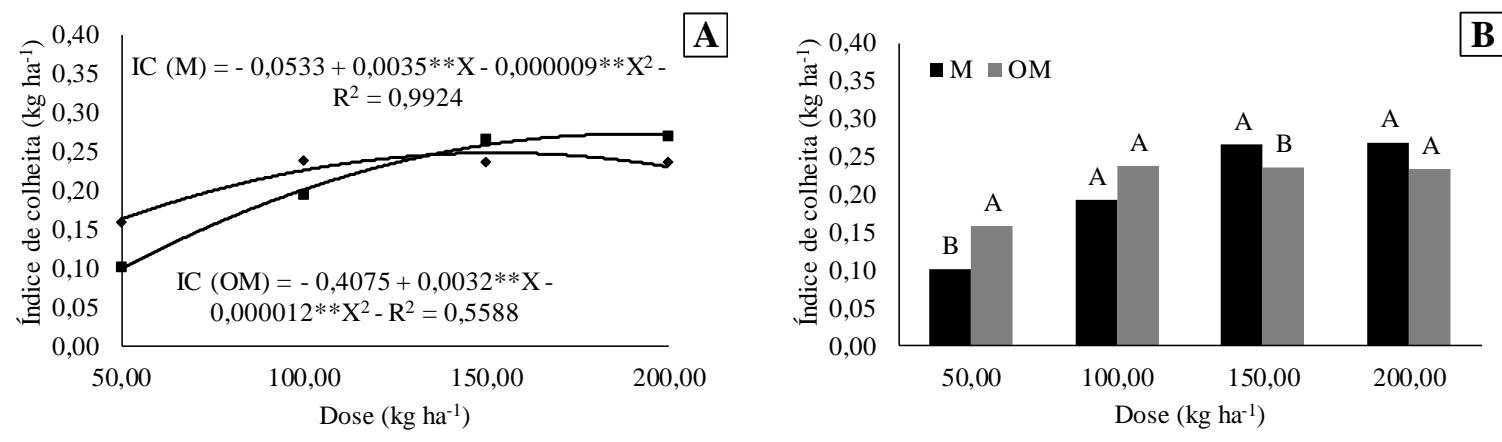

Fonte: Autores.

A biodisponibilidade dos nutrientes provenientes da fonte OM é mais lenta e gradativa, devido a fração orgânica presente nesta fonte, que necessita da ação de microrganismos do solo para que ocorra a mineralização desta fração e os nutrientes fiquem disponíveis à absorção pelas plantas. Devido a isto, resultados inferiores ou semelhante e mais demorados das fontes $\mathrm{OM}$ em detrimento as fontes M são comuns em diversos estudos (Costa et al., 2018).

Como por exemplo o que ocorre com o fósforo, os adubos organominerais disponibilizam este nutriente de forma lenta e a sua solubilização é gradativa, pois a matéria orgânica mineralizada é rica em ácidos húmicos e possui a capacidade de aumentar a disponibilidade de cargas negativas na região de liberação, com o avançar do tempo, esta fonte tende a aumentar a disponibilidade de fósforo (Kiehl, 2008).

\section{Conclusão}

A fonte NPK mineral proporciona maior massa fresca das folhas, massa seca do caule, massa de água e massa seca da parte aérea do girassol do que a fonte orgnomineral.

As doses de 162 e $138 \%$ da recomendação de NPK, via fonte mineral e organomineral proporcionam a maior produtividade de grãos para a cultura do girassol, respectivamente.

O acúmulo de matéria seca, o crescimento e os índices produtivos do girassol apresentaram-se inferiores, quando foi utilizado a fonte orgnomineral na dosagem de $100 \%$ da recomendação, em comparação a fonte mineral, assim é justificáveis num primeiro momento a utilização deste tipo de adubação em culturas anuais, como é o caso do girassol.

\section{Agradecimentos}

O presente trabalho foi realizado com apoio da Coordenação de Aperfeiçoamento de Pessoal de Nível Superior Brasil (CAPES), Ministério da Ciência, Tecnologia, Inovações e Comunicações (MCTIC), à Fundação de Amparo à Pesquisa do Estado de Goiás (FAPEG), ao Conselho Nacional de Desenvolvimento Científico e Tecnológico (CNPq), à Financiadora de Estudos e Projetos (FINEP) e ao Instituto Federal Goiano - Campus Rio Verde (IF Goiano).

\section{Referências}

Andrade, E. M. G., Silva, H. S., Silva, N. S., Sousa Júnior, J. R., \& Furtado, G. F. (2012). Adubação organomineral em hortaliças folhosas, frutos e raízes. Revista Verde, 7(3), 7-11.

Almeida, T., Pocojeski, E., Nesi, C. N., Oliveira, J. P. M., \& Silva, L. S. (2016). Eficiência de fertilizante fosfatado protegido na cultura do milho. Revista Scientia Agraria. 17, 29-35. 
Alvares, C. A., Stape, J. L., Sentelhas, P. C., Gonçalves, J. L. D. M., \& Sparovek, G. (2013). Köppen’s climate classification map for Brazil. Meteorol. Zeitschrift 22, 711-728.

Bernardi, A. C. C., Oliveira Júnior, J. P., Leandro, W. M., Mesquita, T. G. S., Freitas, P. L., \& Carvalho, M. C. S. (2009). Doses e formas de aplicação da adubação potássica na rotação soja, milheto, e algodão em sistema plantio direto. Pesquisa Agropecuária Tropical, 39(2), 158-167.

Castro, C., Moreira, A., Oliveira, R. F., \& Dechen, A. R. (2010). Boro e estresse hídrico na produção do girassol. Ciência e Agrotecnologia, 30(2), 214-220.

Coelho, T. S., Ferreira, J. L. S., \& Calil, F. N. (2017). Produtividade da forrageira Urochloa brizantha (Stapf) Webster e estoque de carbono em um sistema silvopastoril. Enciclopédia Biosfera, Centro Científico Conhecer, 14(26), 550-559.

Costa, F. K. D., Menezes, J. F. S., Almeida Junior, J. J., Simon, G. A., Miranda, B. C., Lima, A. M., \& Lima, M. S. (2018). Desempenho agronômico da soja convencional cultivada com fertilizantes organomineral e mineral. Nucleus, 15(2).

Cruz, S. C. S., Moura, A. G., Machado, C. G., Sena Júnior, D. G., \& Cruz, S. J. S. (2018). Adubação nitrogenada foliar na cultura da soja. Revista Agrotecnologia, 9(1), 54-64.

Dantas, M. S. M., Rolim, M. M., Duarte, A. S., Pedrosa, E. M. R., Tabosa, J. N., \& Dantas, D. C. (2015). Crescimento do girassol adubado com resíduo líquido do processamento de mandioca. Revista Brasileira de Engenharia Agrícola e Ambiental, 19(4), 350-357.

Ferreira, M. M., Fereeira, G. B., Fontes, P. C. R., \& Dantas, J. P. (2006). Índice spad e teor de clorofila no limbo foliar do tomateiro em função de doses de nitrogênio e da adubação orgânica, em duas épocas de cultivo. Revista Ceres, 53(305), 83-92.

Freitas, G. Q., Cabral Filho, F. R., Teixeira, M. B., Alves, D. K. M., Cunha, F. N., Soares, J. A. B., \& Gomes, L. F. (2020). Crescimento e desenvolvimento do girassol irrigado e adubado com organomineral. Research, Society and Development, 9(8), 1-17.

Garcia, J. C., Boneti, J. E. B., Azania, C. A. M., Belucci, L. R., \& Vitorino, R. (2015). Fontes de adubação potássica na lixiviação de potássio em neossolo quartzarênico. Revista Eletrônica Thesis. Ano XII, 24, 76-89.

Gomes, E. M., Ungaro, M. R. G., \& Vieira, D. B. (2003). Influência da suplementação hídrica na altura de planta, diâmetro de capítulo, peso de sementes e produção de grãos. In: Simpósio nacional de girassol, 3., Reunião nacional da cultura de girassol, 15., 2003, Minas Gerais. Anais... Ribeirão Preto: CATI, (CD-ROM).

Gomes, R. F., Silva, A. G., Assis, R. L., \& Pires, F. R. (2007). Efeito de doses e da época de aplicação de nitrogênio nos caracteres agronômicos da cultura do milho sob plantio direto. Revista Brasileira de Ciências do Solo, 31(5), 931-938.

Guareschi, R. F., Gazolla, P. R., Perin, A., \& Santini, J. M. K. (2011). Adubação antecipada na cultura da soja com superfosfato triplo e cloreto de potássio revestidos por polímeros. Ciência e Agrotecnologia, , 35(4), 643-648.

Higashikawa, F. S., \& Menezes Junior, F. O. G. (2017). Adubação mineral, orgânica e organomineral: efeitos na nutrição, produtividade, pós-colheita da cebola e na fertilidade do solo. Scientia Agraria, 18(2).

Kiehl, E. J. (2008). Fertilizantes Organominerais. (2a ed.), Desgaspari Piracicaba - SP.

Köppen, W., \& Geiger, R. (1928.). Klimate der Erde. Gotha: Verlag Justus Perthes. Wall-map.

Kurtz, C., Ernani, P. R., Pauletti, V., Menezes Junior, F. O. G., \& Vieira Neto, J. (2013). Produtividade e conservação de cebola afetadas pela adubação nitrogenada no sistema de plantio direto. Horticultura Brasileira, 31(4), 559-567.

Malaquias, C. A. A., \& Santos, A. J. M. (2017). Adubação organomineral e NPK na cultura do milho (Zea mays L.). PUBVET, 11(5), 501-512.

Nobre, R. G., Gheyi, H. R., Soares, F. A. L., Andrade, L. O., \& Nascimento, E. C. S. (2010). Produção do girassol sob diferentes lâminas com efluentes domésticos e adubação Orgânica. Revista Brasileira de Engenharia Agrícola e Ambiental, 14(7), 747-754.

Oliveira, A. P. S. (2018). Trabalho de conclusão de curso. Produção do milho em função da adubação mineral e organomineral. Agronomia - Anápolis, Unievangélica.

Pereira, M. A. M.et al. (2012). Adubação Organomineral na Cultura do Milho sob Cultivo Consecutivo. Congresso Nacional De Milho E Sorgo, 29. Anais... Águas de Lindóia - 26 a 30 ago.

Queiroz, A. M., Souza, C. H. E., Machado, V. J., Lana, R. M. Q., Korndorfer, G. H., \& Silva, A. A. (2011). Avaliação de diferentes fontes e doses de nitrogênio na adubação da cultura do milho (Zea mays L.). Revista Brasileira de Milho e Sorgo, 10(3), 257-266.

Rosset, E., Colella, J. C., Nascimento Junior, J. R. A., \& Vieira, S. A. (2016). Efeitos de fertilizante organomineral na produção de tomate (lycopersicon esculentum). Revista UNINGÁ Review, 25(2), 12-17.

Santos, H. G., Jacomine P. K. T., Anjos, L. H. C., Oliveira, V. A., Lumbreras, J. F, Coelho, M. R, Almeida, J. A, Araujo Filho, J. C., Oliveira, J. B., \& Cunha, T. J. F. (2018). Sistema Brasileiro de Classificação de Solos. Embrapa, (5a ed.)

Santos, E. N., Mesquita, A. C., Yuri, J. E., Simões, W. L., Souza, M. A., \& Souza, A. R. E. (2020). Fertilizante organomineral no cultivo do meloeiro no submédio Vale do São Francisco. Rev. Agro. Amb., 13(4), 1233-1250.

Santos, J. F., Wanderley, J. A. C., \& Júnior, J. R. S. (2013). Produção de girassol submetido a adubação organomineral. UFCG. Agropecuária Cientifica no semiárido artigo científico, 9(3), 38-44.

Sousa, D. M. G., \& Lobato, E. (2004). (Eds). Cerrado: correção do solo e adubação. 2. ed. Brasília: Embrapa Informação Tecnológica/Embrapa-CPA, 1-416. 
Research, Society and Development, v. 10, n. 6, e4610615396, 2021

(CC BY 4.0) | ISSN 2525-3409 | DOI: http://dx.doi.org/10.33448/rsd-v10i6.15396

Teixeira Filho, A. J., Silveira, E. O., Silva, R. L., \& Carvalho, D. M. G. (2015). Produção de matéria seca total de duas cultivares de milho submetido à adubação mineral e orgânica, Parintins-AM. UFAM/ICSEZ, RECED - Revista Eletrônica Ciência e Desenvolvimento, 12-21.

Tonato, F., Barioni, L. G., Pedreira, C. G., Dantas, O. D., \& Malaquias, J. V. (2010). Desenvolvimento de modelos preditores de acúmulo de forragem em pastagens tropicais. Pesquisa Agropecuária Brasileira, 45, 522-529.

Viana, T. V. A., Santos, A. P. G., Souza, G. G., Neto, L. G. P., Azevedo, B., \& Aquino, B. F. (2013). Trocas gasosas e teores foliares de NPK em meloeiro adubado com biofertilizantes. Revista Brasileira de Ciências Agrárias, 8(4), 595-601. 